\title{
A Case of an Infant Diagnosed with Cow's Milk Allergy and Concurrent Meat Allergy via ImmunoCAP ISAC ${ }^{\circledR}$
}

\author{
So Yoon Jo, Chan Ho Lee, Sung Won Kim, Yoon Ha Hwang \\ Department of Pediatrics, Busan St. Mary's Hospital, Busan, Korea
}

\begin{abstract}
Approximately $13-20 \%$ of infants with milk allergies concurrently exhibit beef allergies. Here, we report a 24-month-old infant who exhibited both pork and beef allergies, concurrently with a milk allergy. The infant's laboratory test results were: 3.73 ISU-E (ISAC standardized unit for IgE) for cow milk $\beta$-lactoglobulin, 23.8 ISU-E for casein, 12.8 ISU-E for cow milk Bos d 6 of serum albumin, and 4.85 ISU-E for cat Fel $\mathrm{d} 2$. This case report summarizes an infant patient diagnosed with a meat allergy that was associated with cow's milk allergy, using ImmunoCAP ISAC ${ }^{\circledR}$. Not only ImmunoCAP ISAC ${ }^{\circledR}$ but also immunocap can be used to diagnose milk allergy and meat allergy at the same time, immunocap testing for component antigen is rare. ImmunoCAP $I_{S A C}{ }^{\circledR}$ is used to diagnose these allergies in our case study, as it has advantage that only $1 \mathrm{ml}$ of blood is needed to run various component antigen tests.
\end{abstract}

Key Words: Atrioventricular block, Bradycardia, General anesthesia

Food allergy is a common disease, especially in children, with prevalence of approximately $6^{-}$ 8\%. ${ }^{1}$ Representative food allergy products include milk, eggs, peanut, fish, shellfish, soybean, wheat, and rice, ${ }^{2}$ although people from different countries or age groups show allergic reactions against different food types. ${ }^{3}$ The main food allergy products for Korean children include eggs, milk, peanut, tree nuts, wheat, fish, meat, sesame, and fruit. ${ }^{4}$ Milk is one of the most common causes of food allergy, accounting for $20 \%$ of all food allergies, with a prevalence ranging from $0.5 \%$ to
$3.2 \%$ in South Korea. ${ }^{4}$ But, the prevalence largely varied between different studies, from $1.9 \%$ to $7.5 \% .^{5-7}$

The prevalence of beef allergies in infant patients is relatively higher (3.3\% to 6.5\%) for infants with atopic dermatitis. ${ }^{8}$ And beef allergy may be present in $0.3 \%$ of the pediatric population. ${ }^{9} \mathrm{~A}$ previous study has shown that $13-20 \%$ of infants with cow's milk allergy also exhibit beef allergy. On the other hand, the risk of developing cow's milk allergy in the infants with beef allergy is even higher. ${ }^{9}$ Here, we report a 24 -months-old boy
Corresponding Author: So Yoon Jo, Department of Pediatrics, Busan St. Mary's Hospital, 25-14, Yongho-ro, 232beon-gil, Nam-gu, Busan 48575, Korea

Tel: +82-51-933-7981 Fax: +82-51-936-7531 E-mail: whthdbs1220@naver.com

\section{(c) (1) (2)}

Articles published in Kosin Medical Journal are open-access, distributed under the terms of the Creative Commons Attribution Non-Commercial License (http://creativecommons.org/licenses/by-nc/4.0/) which permits unrestricted non-commercial use, distribution, and reproduction in any medium, provided the original work is properly cited.
Received: Aug. 30, 2018

Revised: Oct. 04, 2018

Accepted: Oct. 17, 2018 
with cow's milk allergy concurrent beef and pork allergies.

\section{CASE}

The patient was a 24-month-old male, whose father had a history of bronchial asthma and atopic dermatitis. The patient was born by vaginal delivery, with birthweight of $3.2 \mathrm{~kg}$ and without any medical history. There were no pets in the household, and the patient started exhibiting skin flares, itching, and oozing on the skins near the face, neck, and ears at three months of age. At approximately 4 months of age, he experienced urticaria and itching after changing from breast milk to powdered formula. When he started weaning onto food, the urticaria reoccurred after meat (beef, pork) intake. Ever since, patient's mother avoid meat as weaning formula ingredients, and fish and bean was included instead of meat for patient's protein supply.

Based on these observations, the patient was suspected to have food allergies and atopic dermatitis. When urticaria occurred, the patient's vital signs were normal, and no cardiac or pulmonary murmurs were detected via stethoscope. However, skin flares and oozing were observed on the skin near the face, neck, and ears. With the suspicion of allergies, we performed an allergic blood test by immunocap. The allergic test showed absolute eosinophil count (AEC) of 2,210; total IgE level $248.9 \mathrm{U} / \mathrm{mL}$; and specific IgE for cow's milk $72.1 \mathrm{kUA} / \mathrm{L}$ and for casein $23.3 \mathrm{kUA} / \mathrm{L}$ (Table 1). The patient exhibited high antigenicity against milk and casein; and thus, the patient was put on a diet restriction from dairy products, including milk. Furthermore, milk powered formula was changed to casein hydrolytic formula. Nonetheless, the patient's rash symptoms persisted, and eventually, we changed his diet to an amino acid formula. Amino acid formula was supplied to the patient as not only casein allergy, but also lactoglobulin and serum albumin allergy were accompanied to the patient. Whereas casein hydrolytic formula is normally enough for the cow's milk allergy patients who suffer only casein allergy.

He continued to exhibit atopic dermatitis, and an allergic test was performed again at the age of 12 months. This test resulted in AEC 430; total IgE level $994.2 \mathrm{U} / \mathrm{mL}$; and specific IgE for casein $100 \mathrm{kUA} / \mathrm{L}$, for beta-lactoglobulin $26.7 \mathrm{kUA}$, for beef $38.6 \mathrm{kUA} / \mathrm{L}$, and for pork $19.1 \mathrm{kUA} / \mathrm{L}$ (Table 1). These values suggested a meat allergy; and thus, the patient continued to avoid beef and pork.

At 24 months, we performed an ImmunoCAP ISAC $^{\circledR}$ examination for and observed the following the examination measurements: 3.73 ISU-E (ISAC standardized unit for IgE) for cow milk $\beta$ -lactoglobulin, 23.8 ISU-E for casein, 12.8 ISU-E for cow milk Bos d 6 of serum albumin, and 4.85 ISU-E for cat Fel d 2 (Table 2). The reference values for these results are outlined in Table 3.

Based on the patient's characteristic medical history and examination results, we diagnosed 
Table 1. ImmunoCAP results of the patient

\begin{tabular}{llll}
\hline & 4 months & 12 months & Reference range \\
\hline Absolute eosinophil count & 2,210 & 430 & $0-4,000$ \\
Total IgE & $248.9 \mathrm{U} / \mathrm{ml}$ & $994.2 \mathrm{U} / \mathrm{ml}$ & $0-14.9 \mathrm{U} / \mathrm{ml}(4 \mathrm{months})$ \\
& & & $1.4-52.3 \mathrm{U} / \mathrm{ml}(12 \mathrm{months})$ \\
Egg white IgE & $17.1 \mathrm{kUA} / \mathrm{L}$ & $61.0 \mathrm{kUA} / \mathrm{L}$ & $0-0.35 \mathrm{kUA} / \mathrm{L}$ \\
Egg yolk IgE & & $8.79 \mathrm{kUA} / \mathrm{L}$ & $0-0.35 \mathrm{kUA} / \mathrm{L}$ \\
Cow's milk IgE & $72.1 \mathrm{kUA} / \mathrm{L}$ & & $0-0.35 \mathrm{kUA} / \mathrm{L}$ \\
Casein IgE & $23.3 \mathrm{kUA} / \mathrm{L}$ & $100 \mathrm{kUA} / \mathrm{L}$ & $0-0.35 \mathrm{kUA} / \mathrm{L}$ \\
Beta-lactoglobulin IgE & & $26.7 \mathrm{kUA} / \mathrm{L}$ & $0-0.35 \mathrm{kUA} / \mathrm{L}$ \\
Wheat IgE & $0 \mathrm{kUA} / \mathrm{L}$ & $0.16 \mathrm{kUA} / \mathrm{L}$ & $0-0.35 \mathrm{kUA} / \mathrm{L}$ \\
D. farinae IgE & & $38.6 \mathrm{kUA} / \mathrm{L}$ & $0-0.35 \mathrm{kUA} / \mathrm{L}$ \\
Beef IgE & & $19.1 \mathrm{kUA} / \mathrm{L}$ & $0-0.35 \mathrm{kUA} / \mathrm{L} / \mathrm{L}$ \\
Pork IgE & $22.5 \mathrm{kUA} / \mathrm{L}$ & $0-0.35 \mathrm{kUA} / \mathrm{L}$ \\
Potato IgE & & & \\
\hline
\end{tabular}

Table 2. ImmunoCAP ISAC results of the patient at 24 months.

\begin{tabular}{lllll}
\hline Milk & Cow's milk & Bos d 4 & $\alpha$-lactalbumin & 0.48 \\
& & Bos d 5 & B-lactoglobulin & 3.73 \\
& & Bos d 8 & Casein & 23.80 \\
Animals & Bos d lactoferrin & & 0 \\
& Cat & Fel d 1 & Uteroglobulin & 0 \\
& & Fel d 4 & Lipocalin & 0 \\
& Dog & Can f 1 & Lipocalin & 0 \\
\multirow{4}{*}{ Serum albumin } & Can f 2 & Lipocalin & 0 \\
& & Can f 4 & Kallikrein & 0 \\
& Cow & Bos d 6 & & 12.80 \\
& Dog & Can f 3 & & 2.74 \\
& Horse & Equ c 3 & & 0.65 \\
& Cat & Fel d 2 & & 4.85 \\
\hline
\end{tabular}

Table 3. ImmunoCAP ISAC reference value in ISU-E (ISAC Standardized Units for IgE).

\begin{tabular}{ll}
\hline ImmunoCAP ISAC slgE 112 range & Corresponds to ISU-E \\
0 (undetectable or very low) & $<0.3$ \\
1 (low) & $\geq 0.3-<1$ \\
2 (moderate to high) & $\geq 1-<15$ \\
3 (very high) & $\geq 15$ \\
\hline
\end{tabular}

him with cow's milk allergy and concurrent beef and pork allergies. In addition, the patient was also allergic to egg, wheat, and potatoes. The patient was treated with antihistamine and steroid 
ointment, and was recommended to avoid consuming eggs, dairy products, beef, and pork. The patient no longer exhibits food allergic symptoms and is currently being followed-up at an outpatient clinic.

\section{DISCUSSION}

There are three main categories of meat allergies: the immediate meat allergy that is associated with cow's milk allergy, pork-cat syndrome, and alpha-gal syndrome. Pork-cat syndrome is seen in patients sensitized to cat epithelium, which present symptoms suggestive of IgE-mediated hypersensitivity upon ingestion of pork meat. And alpha-gal syndrome, seen in patients with IgE antibodies against the carbohydrate epitope galactose-alpha-1, 3-galactose, have reported severe allergic reactions after consumption of red meat. Age, onset time after intake, and symptoms vary, and component-resolved diagnostics facilitate the differential diagnosis. ${ }^{10}$

The majority of reported reactions to beef in childhood have occurred in cow's milk allergic children. Previous studies have reported that approximately $13-20 \%$ of infant patients with cow's milk allergies also exhibit beef allergies, while 26 out of 28 (92.9\%) infant patients with beef allergies were found to have cow's milk allergies through a double-blinded, placebo-controlled food challenge test and skin prick test. ${ }^{9}$

Key antigens that cause cow's milk allergies in- clude casein, $\beta$-lactoglobulin, $\alpha$-lactalbumin, and bovine serum albumin. ${ }^{11}$ The key allergen proteins from meat that have been discovered hitherto include a $50 \mathrm{kDa}$ protein from chicken, a 51 $\mathrm{kDa}$ protein from pork, $67 \mathrm{kDa}$ bovine serum albumin, and $60 \mathrm{kDa}$ bovine gamma globulin from beef. ${ }^{12,13}$ More specifically, the key protein antigens that cause beef allergies have been shown to act as key antigens for pork and lamb as well, playing an important role as key causative antigens that promote cross-reactions among these meats. ${ }^{8}$ A previous study reported that when an infant patient with beef allergies underwent a skin prick test with lamb and pork antigens, positive results were obtained for $100 \%$ and $50 \%$ of the patients, respectively. In addition, the amino acid sequences for lamb and pork serum albumin show $92.3 \%$ and $78.8 \%$ similarity to the amino acid sequence for bovine serum albumin, respectively. ${ }^{8}$ Therefore, the possibility of cross-reaction between the meat antigens of different species can be explained by the similarity in biochemical structure of serum albumin antigens. This high rate of cross-reaction between beef and milk proteins is caused by bovine serum albumin, a protein antigen that commonly exists in both beef and milk. ${ }^{8,9}$

Recently, in South Korea, a case was reported in which an adult patient with milk allergy simultaneously showed allergic symptoms to beef and pork as measured with the immunoCAP system. ${ }^{5}$

In this case, the patient with cow's milk allergy exhibited identical symptoms after con- 
suming beef, which allowed the clinicians to suspect a possible cross-reaction. Therefore, bovine serum albumin - a protein with the greatest possibility for cross-reaction - was measured using ImmunoCAP ISAC ${ }^{\circledR}$, and we observed significantly higher values compared to the control (normal) group. Furthermore, the level of cat serum albumin was also significantly elevated, suggesting a possible association with serum albumin. Simultaneous allergic symptoms against milk, beef, and pork are thought to be due to sensitization against bovine serum albumin and cat serum albumin.

The case was cross-reacted to cats and pork with milk and beef, and was tested with ImmunoCAP ISAC ${ }^{\circledR}$, a test that has not yet been performed in Korea. This may be different from other cases. The child may also be associated with meat allergy associated with cow's milk allergy and pork-cat syndrome.

Although the prevalence of meat allergies in infant patients is relatively low compared to other food allergies, meat is an important nutritional source, especially for growing infants. Therefore, clinicians must consider the possibility of cross-reaction with other meat antigens in infant patients with cow's milk allergy and perform necessary examinations, when required.

\section{REFERENCES}

1. Sicherer SH, Noone SA, Muñoz-Furlong A. The impact of childhood food allergy on quality of life. Ann Allergy Asthma Immunol 2001;87:461-4.

2. Lee AH, Kim KE, Lee KE, Kim SH, Wang TW, Kim KW, et al. Prevalence of food allergy and perceptions on food allergen labeling in school foodservice among Korean students. Allergy Asthma Respir Dis 2013;1:227-34.

3. Sicherer SH. Epidemiology of food allergy. J Allergy Clin Immunol 2011;127:594-602.

4. Min TK, Pyun BY, Kim HH, Park YM, Jang GC, Kim HY, et al. Epidemiology of food allergy in Korean children. Allergy Asthma Respir Dis 2018;6:4-13.

5. Choi SJ, Hur GY, Shin SY, Park HS. A case of adult onset cow's milk allergy presenting beef and pork meat allergy. Korean J Asthma Allergy Clin Immunol 2007;27:200-3.

6. Eigenmann PA. Anaphylaxis to cow's milk and beef meat proteins. Ann Allergy Asthma Immunol 2002;89:61-4.

7. Mamikoglu B. Beef, pork, and milk allergy (cross reactivity with each other and pet allergies). Otolaryngol Head Neck Surg 2005;133:534-7.

8. Fiocchi A, Restani P, Riva E. Beef allergy in children. Nutrition 2000;16:454-7.

9. Martelli A, De Chiara A, Corvo M, Restani P, Fiocchi A. Beef allergy in children with cow's milk allergy: cow's milk allergy in children with beef allergy. Ann Allergy Asthma Immunol 2002;89:38-43.

10. Matricardi PM, Kleine-Tebbe J, Hoffmann HJ, Valenta R, Hilger C, Hofmaier S, et al. EAACI Molecular Allergology User's Guide. Pediatr Allergy Immunol 2016;27:1-250. 
11. Han GD, Matsuno M, Ito G, Ikeucht Y, Suzuki A. Meat allergy: investigation of potential allergenic proteins in beef. Biosci Biotechnol Biochem 2000;64:1887-95.

12. Ferreira CT, Seidman E. Food allergy: a practical update from the gastroenterological viewpoint. J Pediatr (Rio J) 2007;83:7-20.
13. Werfel SJ, Cooke SK, Sampson HA. Clinical reactivity to beef in children allergic to cow's milk. J Allergy Clin Immunol 1997;99:293-300.

14. Drouet M, Lauret MG, Sabbah A. [The pork-cat syndrome: effect of sensitization to cats on sensitization to pork meat. Apropos of a case]. Allerg Immunol (Paris) 1994;26;305-6. 